\title{
Effect of Cerebral Perfusion Pressure on Acute Respiratory Distress Syndrome
}

\author{
Sonny Thiara, Donald E. Griesdale, William R. Henderson, Mypinder S. Sekhon
}

\begin{abstract}
Background: Increased cerebral perfusion pressure (CPP) $>70 \mathrm{mmHg}$ has been associated with acute respiratory distress syndrome (ARDS) after traumatic brain injury (TBI). Since this reported association, significant changes in ventilation strategies and fluid management have been accepted as routine critical care. Recently, individualized perfusion targets using autoregulation monitoring suggest CPP titration $>70 \mathrm{mmHg}$. Given these clinical advances, the association between ARDS and increased CPP requires further delineation. Objective: To determine the association between ARDS and increased CPP after TBI. Methods: We conducted a single-center historical cohort study investigating the association of increased CPP and ARDS after TBI. We collected demographic data and physiologic data for CPP, intracranial pressure, mechanical ventilation, cumulative fluid balance and delta/driving pressure $(\Delta \mathrm{P})$. We collected outcomes measures pertaining to duration of ventilation, intensive care unit admission length, hospitalization length and 6-month neurological outcome. Results: In total, 113 patients with severe TBI and multimodal neuromonitoring were included. In total, 16 patients (14\%) developed ARDS according to the Berlin definition. There was no difference in the mean CPP during the first 7 days of admission between patients who developed ARDS (74 mmHg SD 18 vs. $73 \mathrm{mmHg}$ SD 18, $p=0.86$ ) versus those who did not. Patients who developed ARDS had a higher $\Delta \mathrm{P}(15 \mathrm{mmHg}$ [5] vs. $12 \mathrm{mmHg}$ [4], $p=0.016)$ and lower lung compliance $\left(35 \mathrm{ml} / \mathrm{cmH}_{2} \mathrm{O}\right.$ [10] vs. $49 \mathrm{ml} / \mathrm{cmH}_{2} \mathrm{O}$ [18], $\left.p=0.024\right)$ versus those who did not. Conclusion: We did not observe an association between increased CPP and ARDS. Patients with ARDS had higher $\Delta \mathrm{P}$ and lower lung compliance.
\end{abstract}

RÉSUMÉ: Les effets de la pression de perfusion cérébrale sur les syndromes de détresse respiratoire aigüe. Contexte: À la suite de traumatismes cranio-cérébraux (TCC), une augmentation de la pression de perfusion cérébrale (PPC) au-dessus de $70 \mathrm{~mm}$ Hg est associée au déclenchement de syndromes de détresse respiratoire aigüe (SDRA). Depuis que cette association a été signalée, des changements notables en ce qui a trait aux stratégies de ventilation et à l'administration de liquides font désormais partie de la panoplie des soins intensifs les plus courants. Plus récemment, des valeurs seuils de perfusion utilisant des techniques de monitorage autorégulé ont suggéré, pour la PPC, une titrimétrie pouvant dépassant les $70 \mathrm{~mm} \mathrm{Hg}$. Considérant ces progrès sur le plan clinique, le lien existant entre les SDRA et une augmentation de la PPC nécessite d'être approfondi. Objectif: Déterminer le lien pouvant exister entre les SDRA et une augmentation de la PPC à la suite de TCC. Méthodes: Dans un seul établissement de santé, nous avons mené une étude de cohorte historique se penchant sur le lien existant entre une augmentation de la PPC et les SDRA à la suite de TCC. Pour ce faire, nous avons collecté auprès de patients des données physiologiques et démographiques se rapportant aux aspects suivants : PPC, pression intracrânienne, ventilation mécanique, équilibre hydrique cumulatif et pression motrice $(\Delta \mathrm{P})$. Nous avons également déterminé des critères d'évaluation se rapportant à la durée de la ventilation, de l'admission aux soins intensifs, de l'hospitalisation mais aussi à l'évolution, sur le plan neurologique, de l'état de santé des patients au bout de 6 mois. Résultats: Au total, 113 patients victimes de TCC sévères et ayant subi un monitorage cérébral multimodal ont été inclus dans cette étude. De ce nombre, 16 d'entre eux, soit $14 \%$, avaient souffert de SDRA selon les critères de la définition de Berlin. Qu'il s'agisse de patients ayant déjà souffert de SDRA (74 mm Hg SD 18 c. 73 mm Hg SD $18 ; p=0,86$ ) ou de ceux jamais atteints par ce syndrome, aucune différence n'a été observée en ce qui a trait à leur PPC moyenne durant les 7 premiers jours d'admission. Cela dit, les patients ayant souffert de SDRA ont montré une pression motrice $(\Delta \mathrm{P})$ plus élevée $(15 \mathrm{~mm} \mathrm{Hg}[5]$ c. $12 \mathrm{~mm} \mathrm{Hg}[4] ; p=0,016)$ et une compliance ou élasticité pulmonaire plus basse $(35 \mathrm{ml} / \mathrm{cmH} 2 \mathrm{O}$ [10] c. $49 \mathrm{ml} / \mathrm{cmH} 2 \mathrm{O}$ [18] ; $p=0,024)$ que ceux n'ayant pas souffert de SDRA. Conclusion: Nous n'avons pas observé de lien entre une augmentation de la PPC et l'apparition de SDRA. Les patients atteints de SDRA ont toutefois montré une pression motrice $(\Delta \mathrm{P})$ plus élevée et une compliance pulmonaire plus basse.

Keywords: Traumatic brain injury, Acute respiratory distress syndrome, Cerebral perfusion pressure, Neuromonitoring, Driving pressure

doi:10.1017/cjn.2017.292

Can J Neurol Sci. 2018; 45: 313-319

From the Department of Medicine, Division of Critical Care Medicine, Vancouver General Hospital, University of British Columbia, Vancouver, BC, Canada (ST, DEG, MSS); Department of Anaesthesiology, Pharmacology and Therapeutics, Vancouver General Hospital, University of British Columbia, Vancouver, BC, Canada (DEG); Center for Clinical Epidemiology and Evaluation, Vancouver Coastal Health Research Institute, University of British Columbia, Vancouver, BC, Canada (DEG); Department of Emergency Medicine,

Division of Critical Care Medicine, Vancouver General Hospital, University of British Columbia, Vancouver, BC, Canada (WRH).

Received September 8, 2017. Final Revisions Submitted October 24, 2017. Date of Acceptance October 31, 2017.

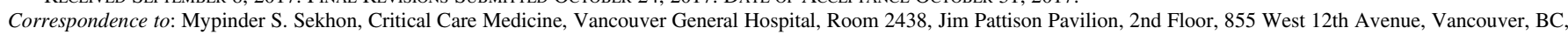
Canada V5Z 1M9. Email: mypindersekhon@gmail.com 


\section{INTRODUCTION}

Traumatic brain injury (TBI) is a major cause of mortality and morbidity worldwide with the long-term outcome being determined by the severity of the underlying intracranial injury and the ensuing secondary injury. ${ }^{1}$ The cornerstone of the critical care management of patients with TBI is to prevent secondary ischemic brain injury by optimizing cerebral oxygen delivery. To achieve this, a critical tenant is to ensure adequate cerebral blood flow (CBF) by maintaining appropriate cerebral perfusion pressure (CPP). ${ }^{2}$

Over the years, there have been numerous, and often conflicting, proposed CPP thresholds. ${ }^{3}$ The Brain Trauma Foundation Guidelines recommend to target a CPP between 60 and $70 \mathrm{mmHg}$ (level IIB). ${ }^{4}$ In addition, they recommend "avoiding aggressive attempts to maintain CPP $>70 \mathrm{mmHg}$ " (level III) due to the risk of acute respiratory distress syndrome (ARDS). ${ }^{4}$ This recommendation is driven from the increased risk of ARDS seen in a randomized study which compared a CBF strategy $(\mathrm{CPP}>70$ $\mathrm{mmHg}$ ) with intracranial pressure (ICP) strategy (CPP $>50$ $\mathrm{mmHg})^{5}$ Although there was no difference in neurologic outcomes, 15 out of $100(15 \%)$ patients in the CBF strategy developed ARDS compared with 3 out of $89(3.3 \%)$ in the ICP strategy. This association between CPP and ARDS has not been observed in other studies of patients with TBI. ${ }^{6,7}$

Recently, there has been increased interest in using autoregulation monitoring which may be useful in determining individualized CPP targets in patients with TBI. ${ }^{8,9}$ Using this approach, patients whose actual CPP was within $5 \mathrm{mmHg}$ of their optimal CPP had improved neurologic outcomes. ${ }^{10}$ Interestingly, the actual mean CPP for the study period was $78 \mathrm{mmHg}$ (SD 8), higher than the threshold as recommended by the Brain Trauma Foundation. ${ }^{4}$

Thus, there appears to be conflicting evidence concerning CPP thresholds in patients with TBI. Whereas targeting individualized CPP thresholds greater than $70 \mathrm{mmHg}$ may be beneficial in some patients, this must be weighed against the risk of developing ARDS. However, the risk of ARDS has not previously been well characterized.

As such, our objective was to conduct a single-center historical cohort study to characterize the incidence, etiology and outcomes of ARDS in patients admitted with severe TBI who underwent multimodal neuromonitoring. We additionally wanted to examine the association between CPP, dose of vasopressors, ventilation parameters (positive end expiratory pressure $[\mathrm{PEEP}]$ and driving pressure $[\Delta \mathrm{P}]$ ) and cumulative fluid balance on the risk of developing ARDS.

\section{Material AND Methods}

We performed an historical cohort study. This study is the same cohort of patients as reported in our prior published quasiexperimental uncontrolled before-and-after study. ${ }^{11} \mathrm{We}$ report this results in accordance with the Strengthening the Reporting of Observational Studies in Epidemiology (STROBE) statement. ${ }^{12}$ This study was approved by both the University of British Columbia and hospital clinical research ethics boards who waived the requirement for written informed consent (H16-01100).

\section{Study population and hospitals}

Patients were included in our cohort if they were admitted to the intensive care unit (ICU) at Vancouver General Hospital with a diagnosis of severe TBI, as defined by a post-resuscitation Glasgow Coma Score $(\mathrm{GCS}) \leq 8$ between February 2010 and
May 2016, and in whom an ICP monitor was inserted. Patients were excluded if their pupils were bilaterally dilated and unresponsive to light. The ICU at Vancouver General Hospital is a closed, 34-bed mixed medical-surgical unit that operates on an approximate 1:1.2 nurse-to-patient ratio. Affiliated with the University of British Columbia, the ICU is staffed by fellowship trained subspecialty critical care medicine physicians and specialty residents in attendance.

\section{Data collection}

Patients were identified using the Provincial ICU database. Data were abstracted from the medical record into a standardized casereport form in Microsoft Excel $2013^{\circledR}$ (Redmond, Washington, DC, USA). In addition to demographic data, the following baseline data were abstracted: post-resuscitation GCS, pupillary abnormalities (one pupil dilated, both pupils dilated), pre-hospital hypoxia $\left(\mathrm{SpO}_{2}<92 \%\right)$ or hypotension (systolic blood pressure $<90 \mathrm{mmHg}$ ), and Rotterdam score on the initial computerized tomography head exam. ${ }^{13}$ We collected the following variables for the first 7 days: temperature $\left({ }^{\circ} \mathrm{C}\right)$, medications administered (propofol, norepinephrine, neuromuscular blockers, barbiturates, hydrocortisone, fludrocortisone and midazolam), intravenous fluids per day (ml) (crystalloids, colloids, red blood cells and mannitol), laboratory values (hemoglobin, troponin and serum sodium) and arterial blood gases $(\mathrm{pH}$, partial pressure of oxygen and carbon dioxide). We also collected the following daily mean ventilation data: peak and plateau pressure, minute ventilation and PEEP. Driving pressure was calculated by subtracting the PEEP from the plateau pressure. Daily chest radiographs were read independently by two authors (ST and MS) who were unaware of the other clinical parameters. The chest radiographs were read documenting the presence or absence of bilateral infiltrates in keeping with ARDS. Neurophysiologic data (mean arterial pressure [MAP], $\mathrm{ICP}, \mathrm{CPP}, \mathrm{PbO}_{2}$ and pressure reactivity index [PRx]) were recorded in real-time and continuously at 10 -second intervals from our bedside monitors directly onto the ICM $+{ }^{\circledR}$ brain monitoring software program (Division of Neurosurgery, Cambridge University). These variables were then averaged for each day. We also collected procedural data, including: surgical interventions (decompressive craniectomy, craniotomy, external ventricular drain, tracheostomy), medical interventions (therapeutic hypothermia, barbiturate use, days of intravenous sedation) and invasive neuromonitoring (days of monitoring, jugular venous oximetry, intra-parenchymal ICP, $\mathrm{PbO}_{2}$ and PRx). The following outcome data were obtained from the ICU database: intensive care and hospital days, days of mechanical ventilation and hospital mortality. Neurologic outcomes were assessed using the Glasgow Outcome Scale and were determined at 6 months by telephone interview. Glasgow Outcome Scale is an ordinal scale between 1 and 5, where: 1 -death, 2-permanently vegetative state, 3 - severe disability (requires help with activities of daily living), 4 -moderate disability and 5-good recovery.

\section{Pressure Reactivity Index and Optimal Cerebral Perfusion Pressure-Guided Management}

Pressure reactivity index, is the moving correlational coefficient between MAP and ICP. Pressure reactivity index is a measure of autoregulation that can be monitored in real time using the ICM+ monitoring software program. Mean arterial pressure and ICP numerical data are streamed into a laptop from our bedside monitors (Carescape; General Electric, New York, NY, USA) via a USB-RS232 to serial adapter cable. Pressure reactivity index 
is generated from 30 consecutive 10-second averaged values of ICP and MAP. This methodology has been described in previous studies as a valid measure of autoregulation after severe TBI. ${ }^{14,15}$

By plotting the entire CPP range in $5 \mathrm{mmHg}$ bins ( $x$ axis) versus the absolute PRx ( $y$ axis), U-shaped curves can be generated with the nadir reflecting the optimal CPP. Identification of the optimal CPP is conducted on a daily basis and a $10 \mathrm{mmHg}$ CPP range is prescribed every 24 hours while multimodal monitoring is place. Optimal CPP-guided management based on PRx is used in our unit on the basis of previous published studies and guideline statements. ${ }^{9,14}$ In the setting of complete dysfunctional autoregulation (i.e., PRx $>0.3$ ), we individualize CPP targets based on the minimum CPP required to achieve adequate brain oxygenation $\left(\mathrm{PbO}_{2}>20 \mathrm{mmHg}\right)$, while weighing the risks of excessive iatrogenic complications (fluid administration and vasopressor doses).

\section{Definition of Acute Respiratory Distress Syndrome}

We used the Berlin criteria to define ARDS. ${ }^{13}$ A patient was considered to have ARDS if they had an acute onset of bilateral opacities consistent with pulmonary edema (on either chest X-ray or CT scan) with a $\mathrm{PaO}_{2}$ to $\mathrm{FiO}_{2}(\mathrm{PF})$ ratio $\leq 300 \mathrm{mmHg}$ that is not fully explainable by heart failure or volume overload. Acute respiratory distress syndrome was characterized as either mild $(200 \mathrm{mmHg}<\mathrm{PF} \leq 300 \mathrm{mmHg})$, moderate $(100 \mathrm{mmHg}<\mathrm{PF} \leq$ $200 \mathrm{mmHg}$ ) or severe ( $\mathrm{PF} \leq 100 \mathrm{mmHg}$ ). The underlying etiology of ARDS was adjudicated by two authors (ST and MS).

\section{Management of Traumatic Brain Injury Patients}

The management of patients admitted with a TBI at our institution has previously been reported. ${ }^{11}$ Our TBI management protocol is modeled after other published protocols. ${ }^{16}$ Patients are managed in a tiered fashion depending on the degree of intervention required to control their ICP below 20-25 mmHg. During the time of this study (November 2014), we transitioned our neuromonitoring from solely the use of external ventricular drains with jugular venous oximetry, to the Camino ${ }^{\circledR}$ parenchymal ICP and Licox ${ }^{\circledR} \mathrm{PbO}_{2}$ monitors (Integra ${ }^{\circledR}$ Life Sciences, Plainsboro, $\mathrm{NJ}$, USA). Individualized CPP thresholds are set using $\mathrm{PbO}_{2}$ and autoregulation monitoring with PRx. ${ }^{17}$

\section{Statistical Analysis}

All analyses were performed using Stata 10.0 (StataCorp, TX, USA). All tests of hypothesis tests were two-sided and we considered a $p$-value of less than 0.05 to be statistically significant. Normally distributed, non-normally distributed and categorical data were described with mean (SD), median (interquartile range [IQR]) and proportion (percent), respectively. Univariable comparisons of continuous variables were performed using independent $t$-tests for normally distributed data and Wilcoxon rank-sum test for non-normally distributed data. The sample size was one of convenience. A complete-case analysis was performed and missing data are presented when applicable. We sought to determine the association between ventilation parameters ( $\triangle \mathrm{P}$ and PEEP), cumulative fluid balance, CPP and use of norepinephrine on the risk of ARDS. Owing to the repeated measures nature of the data structure, we performed a generalized linear regression to model the association of these variables and the risk of ARDS.

\section{RESULTS}

Between February 2010 and May 2016, there were 115 patients identified using the ICU database. We excluded two patients who presented with unreactive and dilated pupils, leaving 113 patients included in the final analysis. The cohort had a mean age of 39 years (SD 17) and 26 out of 113 (23\%) were female. The median GCS motor score was 3 (IQR 1-4). The demographic and admission characteristics are presented in Table 1 . The clinical interventions and patient outcomes are presented in Table 2. Of note, there were no missing data.

\section{Characteristics of patients developing Acute Respiratory Distress Syndrome}

Overall, 16 out of 113 (14\%) patients developed ARDS in the first 7 days of admission. There was a total of 46 out of $694(6.6 \%)$ patient days where the criteria of ARDS were met. Seven out of the 16 patients met ARDS criteria on the 1st day of admission with two and three patients developing ARDS on admission days 2 and 3 , respectively. Four out of 16 patients developed ARDS between days 5 and 7. Regarding the severity of ARDS, 10 out of $16(68 \%)$ were mild and 6 out of $16(38 \%)$ were moderate. There were no cases of severe ARDS.

The etiology of ARDS were as follows: aspiration pneumonia (8 out of 16), pulmonary contusion (4 out of 16) and sepsis (4 out of 16). The median duration of ARDS was 4 days (IQR 2-7.5). Comparing patients who developed ARDS to those who did not develop ARDS, there was no difference in mechanical ventilationfree days, sedation-free days, ICU-free days or duration of hospitalization in days (Table 2).

\section{Relationship of Acute Respiratory Distress Syndrome to Cerebral Perfusion Pressure, ventilation parameters, cumulative fluid balance}

There was no difference in CPP during the first 7 days between those patients who developed ARDS (74 mmHg [15]) compared

Table 1: Baseline characteristics of cohort

\begin{tabular}{l|c|c|c}
\hline & $\begin{array}{c}\text { Total Cohort } \\
(\boldsymbol{n}=\mathbf{1 1 3})\end{array}$ & $\begin{array}{c}\text { ARDS } \\
(\boldsymbol{n}=\mathbf{1 6})\end{array}$ & $\begin{array}{c}\text { No-ARDS } \\
(\boldsymbol{n}=\mathbf{9 7})\end{array}$ \\
\hline Age in years (mean $[\mathrm{SD}])$ & $39(17)$ & $41(18)$ & $38(17)$ \\
\hline Female (gender, $n[\%])$ & $26(23)$ & $5(31)$ & $21(22)$ \\
\hline Admission hypotension $(n[\%])$ & $40(35)$ & $9(56)$ & $31(32)$ \\
\hline Admission hypoxemia $(n[\%])$ & $26(23)$ & $5(31)$ & $21(22)$ \\
\hline $\begin{array}{l}\text { Glasgow Coma Scale median } \\
\text { motor score }(\mathrm{IQR})\end{array}$ & $3(1-4)$ & $3.5(1-4)$ & $3(1-4)$ \\
\hline One pupil non-reactive $(n[\%])$ & $33(29)$ & $5(31)$ & $28(29)$ \\
\hline Mechanism of injury $(n[\%])$ & & & $30(31)$ \\
\hline $\begin{array}{l}\text { Motor vehicle or motor cycle } \\
\text { accident }\end{array}$ & $34(30)$ & $4(25)$ & $37(38)$ \\
\hline Accidental fall & $45(40)$ & $8(50)$ & $20(21)$ \\
\hline Pedestrian or cyclist struck & $24(21)$ & $4(25)$ & $10(10)$ \\
\hline Other & $10(9)$ & 0 & $4(3-4)$ \\
\hline Rotterdam score, median $(\mathrm{IQR})$ & $3(3-4)$ & $3(3-4)$ &
\end{tabular}

$\mathrm{ARDS}=$ acute respiratory distress syndrome; $\mathrm{IQR}=$ interquartile range. 
Table 2: Clinical interventions and outcomes stratified by patients who developed acute respiratory distress syndomre (ARDS)

\begin{tabular}{|c|c|c|c|c|}
\hline & Total cohort $(n=113)$ & $\operatorname{ARDS}(n=16)$ & No-ARDS $(n=97)$ & $p$-value \\
\hline Parenchymal ICP catheter use ( $n[\%])$ & $26(23)$ & $4(25)$ & $22(23)$ & 0.76 \\
\hline $\mathrm{PbtO}_{2}$ catheter use $(n[\%])$ & $26(23)$ & $4(25)$ & $22(23)$ & 0.76 \\
\hline EVD use $(n[\%])$ & $91(81)$ & $12(75)$ & $79(81)$ & 0.51 \\
\hline Craniotomy performed $(n[\%])$ & $57(50)$ & $12(75)$ & $45(46)$ & 0.057 \\
\hline Craniectomy performed $(n[\%])$ & $38(34)$ & $6(38)$ & $32(33)$ & 0.78 \\
\hline ICU days, median (IQR) & $13(7-18)$ & $13.5(11.5-21)$ & $12(6.5-16.5)$ & 0.055 \\
\hline Mechanical ventilation days (median [IQR)) & $11(6-15)$ & $13.5(11-18)$ & $10(6-15)$ & 0.017 \\
\hline Neuromonitoring days (median [IQR]) & $6(4-8)$ & $7(5-11)$ & $6(4-8)$ & 0.30 \\
\hline Sedation days (median [IQR]) & $6(4-9)$ & $6(4-8)$ & $6(4-16.5)$ & 0.27 \\
\hline Hospital days (median [IQR]) & $42(22-68)$ & $45.5(23.5-132.5)$ & $41(20-65)$ & 0.31 \\
\hline Tracheostomy performed ( $n[\%])$ & $69(61)$ & $13(81)$ & $56(57)$ & 0.098 \\
\hline Glasgow Outcome Score at 6 months & & & & 0.11 \\
\hline Death & $24(21)$ & $5(31)$ & $19(20)$ & \\
\hline Permanently vegetative state & $11(10)$ & $3(19)$ & $8(8)$ & \\
\hline Severe disability & $28(25)$ & $3(19)$ & $25(26)$ & \\
\hline Moderate disability & $29(26)$ & $5(31)$ & $24(25)$ & \\
\hline Good recovery & $21(19)$ & 0 & $21(22)$ & \\
\hline Favorable neurologic outcome (GOS 4 or 5 ) & $50(44)$ & $5(31)$ & $45(46)$ & 0.29 \\
\hline
\end{tabular}

$\mathrm{ICP}=$ intracranial pressure; $\mathrm{EVD}=$ external ventricular drain; $\mathrm{ICU}=$ intensive care unit; $\mathrm{IQR}=$ interquartile range; GOS = Glasgow Outcome Scale

with those patients who did not develop ARDS (73 $\mathrm{mmHg}[18])$. Ventilation parameters $(\Delta \mathrm{P}$ and PEEP), $\mathrm{PF}$ ratio, $\mathrm{CPP}$ and cumulative fluid balance stratified by day of admission and ARDS are presented in Table 3 and Figure 1. Patients who developed ARDS had a higher $\Delta \mathrm{P}$ during the first 7 days $(15 \mathrm{mmHg}$ [5]) compared with those patients who did not develop ARDS (12 mmHg [4]) $(p=0.016)$. Compliance was also lower over the first 7 days comparing those patients who had ARDS $(35 \mathrm{ml} /$ $\mathrm{cmH}_{2} \mathrm{O}$ [10]) to those who did not have ARDS $\left(49 \mathrm{ml} / \mathrm{cmH}_{2} \mathrm{O}\right.$
[18]) $(p=0.024)$. There was no difference in PEEP, $\mathrm{PaCO}_{2}$, cumulative fluid balance or norepinephrine dose.

\section{Discussion}

The goal of our historical cohort study was to characterize the incidence, characteristics and etiology of patients admitted with a severe TBI requiring multimodal monitoring, who fulfilled the Berlin criteria for ARDS. ARDS occurred in 16 out of 113 patients.

Table 3: Cerebral perfusion pressure (CPP), intracranial pressure, $\triangle P, P E E P$ and cumulative fluid balance stratified by acute respiratory distress syndomre (ARDS) for the first 7 days of intensive care unit admission

\begin{tabular}{|c|c|c|c|c|c|c|c|c|c|}
\hline Variables & & Day 1 & Day 2 & Day 3 & Day 4 & Day 5 & Day 6 & Day 7 & $p$-value \\
\hline \multirow[t]{2}{*}{$\mathrm{CPP}(\mathrm{mmHg})$} & ARDS & $67(15)$ & $73(11)$ & 74 (13) & $75(12)$ & $76(13)$ & 77 (14) & $73(25)$ & 0.86 \\
\hline & No-ARDS & 69 (19) & 70 (19) & 72 (17) & 73 (18) & 76 (17) & $76(17)$ & 76 (19) & \\
\hline \multirow[t]{2}{*}{ ICP $(\mathrm{mmHg})$} & ARDS & $19(18)$ & $14(7)$ & $14(6)$ & $12(6)$ & $12(5)$ & $12(5)$ & $12(5)$ & 0.88 \\
\hline & No-ARDS & $14(9)$ & $14(9)$ & $16(10)$ & $15(8)$ & $14(6)$ & $14(6)$ & $14(6)$ & \\
\hline \multirow[t]{2}{*}{$\Delta \mathrm{P}\left(\mathrm{cmH}_{2} \mathrm{O}\right)$} & ARDS & $15(11-17)$ & $12(11-14)$ & $14(12-17)$ & $15(13-16)$ & $15(14-19)$ & $16(13-18)$ & $17(13-19)$ & 0.016 \\
\hline & No-ARDS & $11(9-15)$ & $11(9-14)$ & $11(9-14)$ & $12(9-15)$ & $12(10-15)$ & $12(10-16)$ & $13(11-17)$ & \\
\hline \multirow[t]{2}{*}{$\mathrm{PEEP}\left(\mathrm{cmH}_{2} \mathrm{O}\right)$} & ARDS & $5(5-8)$ & $5(5-8)$ & $7(5-9)$ & $8(5-8)$ & $5(5-8)$ & $5(5-10)$ & $7(5-10)$ & 0.104 \\
\hline & No-ARDS & $5(5-5)$ & $5(5-5)$ & $5(5-5)$ & $5(5-6)$ & $5(5-8)$ & $5(5-7)$ & $5(5-5)$ & \\
\hline \multirow[t]{2}{*}{ PF ratio } & ARDS & $227(65)$ & $228(39)$ & $214(48)$ & $200(36)$ & $217(39)$ & $246(30)$ & $259(27)$ & $<0.001$ \\
\hline & No-ARDS & 403 (148) & $406(146)$ & 373 (102) & $251(105)$ & $353(98)$ & $337(92)$ & $341(102)$ & \\
\hline \multirow[t]{2}{*}{ Cumulative balance $(\mathrm{ml})$} & ARDS & $2248(1990)$ & $4969(3227)$ & $7258(4413)$ & 8977 (5032) & $9973(5131)$ & $10377(5054)$ & $10340(4207)$ & 0.47 \\
\hline & No-ARDS & $2153(1580)$ & $4772(2591)$ & $7011(3662)$ & $8150(3918)$ & $8981(4271)$ & $9357(4882)$ & $9978(4283)$ & \\
\hline
\end{tabular}

$\mathrm{ICP}=$ intracranial pressure; $\Delta \mathrm{P}=$ driving/delta pressure; $\mathrm{PEEP}=$ positive end expiratory pressure; $\mathrm{PF}$ ratio $=\mathrm{PaO}_{2}$ to $\mathrm{FiO}_{2}$ ratio.

Standard deviations are recorded next to absolute mean values in parentheses. 

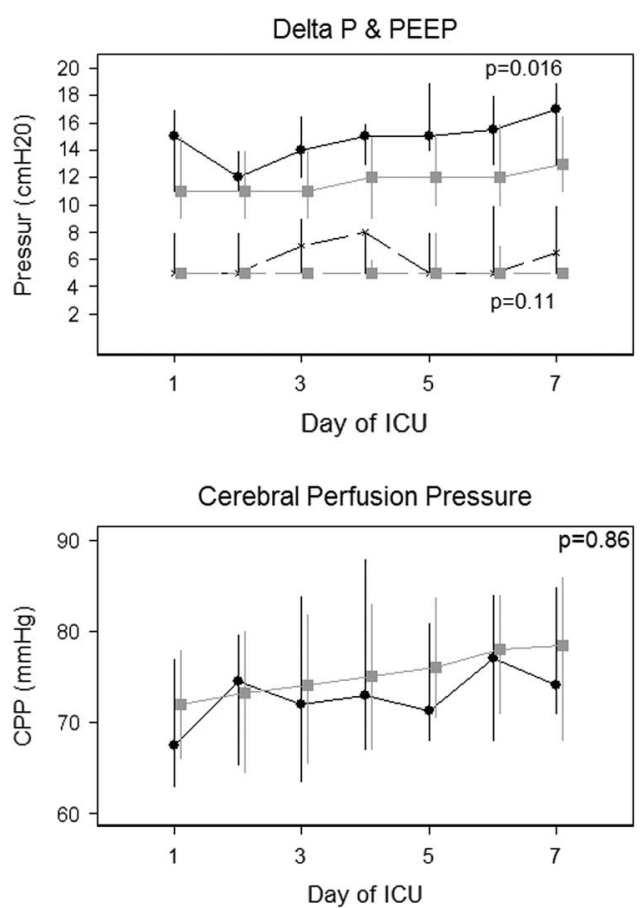
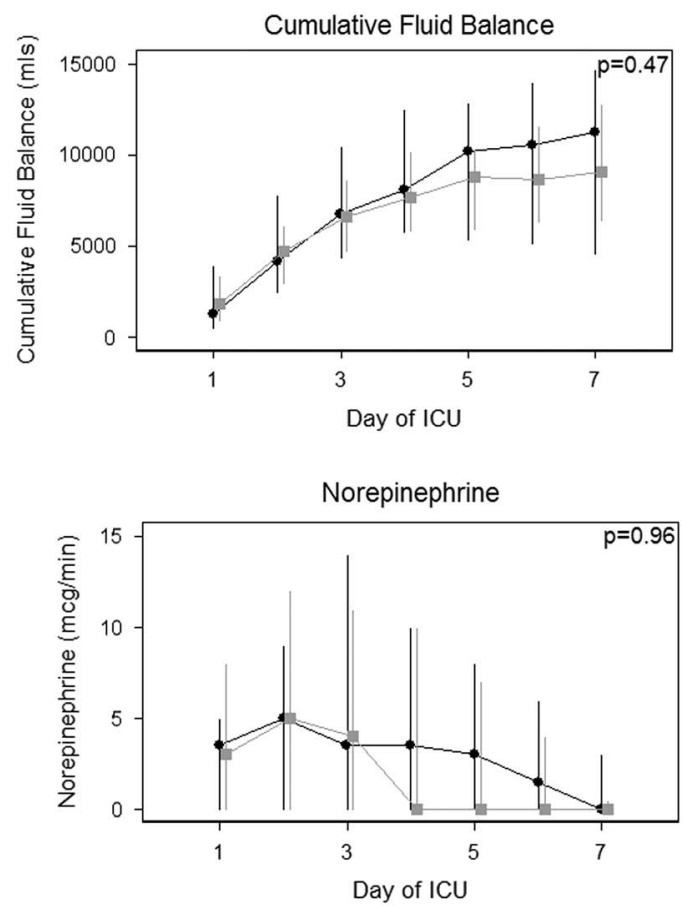

No ARDS

Figure 1: Depicted are differences in cerebral perfusion pressure (CPP), ventilation parameters (PEEP and $\Delta P)$, norepinephrine doses $(\mathrm{mcg} / \mathrm{min})$ and cumulative fluid balance $(\mathrm{ml})$ in patients who developed acute respiratory distress syndrome versus those who did not. $\Delta P=$ driving pressure; $P E E P=$ positive end expiratory pressure; ICU = intensive care unit; $A R D S=$ acute respiratory distress syndrome.

The vast majority of cases of ARDS were due to aspiration pneumonia and was mild in severity. There was no difference in CPP, cumulative fluid balance or norepinephrine dose between patients who developed ARDS and those who did not. Patients who developed ARDS had higher $\Delta \mathrm{P}$ and lower respiratory system compliance. Finally, there was no difference in the two groups in mechanical ventilation-free days, sedation-free days, ICU-free days and duration of hospitalization.

The incidence of ARDS in patients with severe TBI varies between $7.7 \%$ and $30 \%$, with rates being similar between both the Berlin and previous American European Consensus Conference (AECC) definitions. ${ }^{18,19}$ Robertson et al. ${ }^{5}$ performed a randomized trial comparing a CBF-target protocol to an ICP-targeted protocol. The major difference between these two protocols was that CPP was maintained $>70 \mathrm{mmHg}$ in the CBF-targeted group, compared with $>50 \mathrm{mmHg}$ in the ICP-targeted group. Overall, ARDS occurred in 18 out of 189 patients (9.5\%): 15 out of 100 (15\%) of patients in the CBF strategy compared with 3 out of 89 $(3.3 \%)$ in the ICP strategy. In a subsequent analysis of these 18 patients who developed ARDS, the identified risk factors were: administration of epinephrine (odds ratio [OR] 5.7, 95\% confidence interval [CI]: 1.0-34.3), administration of dopamine (OR 10.8, 95\% CI: 1.4-488) and a history of drug abuse (OR 3.1, 95\% CI: $0.93-11.2) .{ }^{20}$ In the study by Robertson et al., the PF ratio used to define ARDS was $\leq 200 \mathrm{mmHg}$. Using the same PF ratio, the incidence of ARDS in our study was much lower, only 6 of $113(5 \%)$. In contrast to the studies by Robertson et al., we did not demonstrate an association between either CPP or vasopressor dose and the development of ARDS.
Using the Berlin criteria for ARDS, Hendrickson et al. ${ }^{7}$ observed an incidence of ARDS within the first 8 days in patients admitted with a severe TBI of $30 \%$. Of the 62 cases of ARDS in their study, $32 \%$ were mild, $49 \%$ were moderate and $19 \%$ were severe. Following multivariable adjustment, male sex and platelet transfusion in the first 12 hours were associated with the risk of developing ARDS. Furthermore, despite no difference in mortality, those patients who developed ARDS had increased length of stay and fewer ventilator-free days. However, despite a higher incidence of ARDS in their study, there was no description of the etiology of ventilator parameters of those patients who developed ARDS.

One interesting finding in our study was the association of $\Delta \mathrm{P}$ and the development of ARDS. Driving pressure $(\Delta \mathrm{P}=$ tidal volume/respiratory system compliance) essentially normalizes the delivered tidal volume to the respiratory system compliance. In a recent large observational study of 3,562 patients enrolled into nine randomized trials of patients with ARDS, $\Delta \mathrm{P}$, rather than PEEP or tidal volume, was found to be the respiratory parameter most strongly associated with survival. ${ }^{21}$ Guerin et al. ${ }^{22}$ found a $5 \%$ increase in the risk of death for each $\mathrm{cmH}_{2} \mathrm{O}$ increase in $\Delta \mathrm{P}$. The association of $\Delta \mathrm{P}$ and ARDS has also been demonstrated in a recent multicenter observational study in neurocritically ill patients. $^{23}$

Physiologically, the development of ARDS may pose significant concerns for patients with TBI. First, ARDS can cause profound arterial hypoxemia which is associated with concomitant brain hypoxia and secondary injury. ${ }^{24}$ Second, permissive hypercapnia with low tidal volume ventilation, a mainstay in 
the ventilation management of ARDS, may be poorly tolerated in patients with TBI. ${ }^{25}$ Carbon dioxide, a potent cerebral vasodilator, increases $\mathrm{CBF}$ and volume, which can cause dangerous elevations in ICP in patients with limited intracranial compliance. ${ }^{25,26}$ Furthermore, hypercapnia can distort cerebral autoregulation by narrowing the intact zone of autoregulation and resulting in a rightward shirt of the lower limit of intact autoregulation, rendering the injured brain susceptible to ischemia. ${ }^{27}$ Finally, mechanical ventilation, specifically application of positive expiratory pressure has been associated with increased intrathoracic pleural pressure and subsequent increased ICP. ${ }^{28-30}$ However, this latter relationship may not hold in the setting of poor lung compliance. ${ }^{31}$

The obvious conflict here is that the modifiable variables used to maintain an optimal CPP, namely vasopressors and fluids, have previously been associated with the risk of developing ARDS, which itself carries morbidity to the patient. This is reflected in the Brain Trauma Foundation Guidelines which specifically recommend "avoiding aggressive attempts to maintain CPP $>70 \mathrm{mmHg}$ " (level III) due to the risk of ARDS. ${ }^{4}$ In contrast, the international multidisciplinary consensus conference on multimodality monitoring in neurocritical care does not specify specific CPP targets. Rather, they recommend that individualized CPP targets and that autoregulation monitoring may be useful in determining optimal CPP. ${ }^{9}$ There is an association with improved neurologic outcomes when patients actual $\mathrm{CPP}$ is close to their optimal CPP. ${ }^{10}$ Although associated with better neurologic outcomes, this individualized approach to CPP management often results in higher CPP than recommended by the Brain Trauma Foundation. In fact, the mean CPP in patients who achieved good neurologic outcomes was $79 \mathrm{mmHg}$ (SD 7). Sorrentino et al. ${ }^{32}$ identified thresholds for values for ICP, CPP and pressure reactivity using a database of 459 patients with TBI. They found that for patients with impaired autoregulation, those with CPP $<70 \mathrm{mmHg}$ had significantly worse outcomes. ${ }^{32}$ Thus, given the increasingly clinical evidence supporting individualized CPP, which is often higher than $70 \mathrm{mmHg}$, the risk of developing ARDS, with its associated outcomes, needs to be characterized.

There are several significant limitations to our study that require consideration when interpreting our results. The most obvious limitation is small sample size as we only had 16 cases of ARDS in our cohort using the Berlin criteria. We believe this incidence to be correct and unlike prior studies in patients with TBI, we determined the underlying etiology of ARDS. However, the small sample size greatly limits the inference of associations with the variables of interest, namely: CPP, use of vasopressors and cumulative fluid balance. Furthermore, only nine patients developed "late" ARDS whereby the development of ARDS occurred after the first 48 hours of admission which would more accurately reflect the effect of increased CPP, vasopressor dose or fluid administration pm the occurrence of ARDS. Future logical next steps include further interrogating the potential associations between vasopressor doses and increased CPP in a larger cohort. In addition, because of the observational nature of the study, we are unable to clarify the direction of association between $\Delta \mathrm{P}$ and ARDS. In other words, it may be that clinicians used higher pressures in those patients who developed ARDS, rather than $\Delta \mathrm{P}$ leading to ARDS. Because of the low event rate of ARDS, we were unable to perform an adjusted analysis. Thus, confounding is clearly an alternate explanation for our findings. The strengths of our study include a detailed characterization of the etiology of ARDS, and a repeated measures analysis for longitudinal data structure.

\section{Conclusion}

In conclusion, the risk of ARDS in our cohort of TBI is lower than previously reported. Patients who developed ARDS had similar outcomes to those who did not develop ARDS. Although we have few outcomes events, there was no association with the development of ARDS and CPP, fluid balance or vasopressor dose. Finally, we demonstrated an association between $\Delta \mathrm{P}$ and the risk of developing ARDS.

\section{ACKNOWLEDGMENT}

The authors acknowledge the Vancouver general Hospital ICU staff for their support.

\section{Disclosures}

ST, DEG, WRH, and MSS have nothing to disclose.

\section{Statement of Authorship}

ST is the primary author and contributed the majority of the manuscript preparation and background research. DEG contributed to data analysis and manuscript preparation. WRH contributed to manuscript preparation. MSS contributed is the senior author, contributed to data collection, analysis and manuscript preparation. All authors read and approved the final manuscript.

\section{REFERENCES}

1. Ghajar J. Traumatic brain injury. Lancet. 2000;356:923-9.

2. Czosnyka M, Pickard J. Monitoring and interpretation of intracranial pressure. J Neurol Neurosurg Psychiatry. 2004;75:813-21.

3. Robertson CS. Management of cerebral perfusion pressure after traumatic brain injury. Anesthesiology. 2001;95:1513-17.

4. Carney N, Totten AM, O'Reilly C, et al. Guidelines for the management of severe traumatic brain injury, fourth edition. Neurosurgery. 2017;80(1):6-15.

5. Robertson CS, Valadka AB, Hannay HJ, et al. Prevention of secondary ischemic insults after severe head injury. Crit Care Med. 1999;27:2086-95.

6. Rincon F, Ghosh S, Dey S, et al. Impact of acute lung injury and acute respiratory distress syndrome after traumatic brain injury in the United States. Neurosurgery. 2012;71:795-803.

7. Hendrickson CM, Howard BM, Kornblith LZ, et al. The acute respiratory distress syndrome following isolated severe traumatic brain injury. J Trauma Acute Care Surg. 2016;80: 989-97.

8. Czosnyka M, Brady K, Reinhard M, Smielewski P, Steiner LA. Monitoring of cerebrovascular autoregulation : facts, myths, and missing links Neurocrit Care. 2009:373-86.

9. Le Roux P, Menon DK, Citerio G, et al. Consensus summary statement of the International Multidisciplinary Consensus Conference on Multimodality Monitoring in Neurocritical Care : a statement for healthcare professionals from the Neurocritical Care Society and the European Society of Intensive. Intensive Care Med. 2014;40:1189-209.

10. Aries MJ, Czosnyka M, Budohoski KP, et al. Continuous determination of optimal cerebral perfusion pressure in traumatic brain injury. Crit Care Med. 2012;40:2456-63.

11. Sekhon MS, Gooderham P, Toyota B, et al. Implementation of neurocritical care is associated with improved outcomes in traumatic brain injury. Can J Neurol Sci. 2017;44(4):350-7. 
12. Vandenbroucke JP, von Elm E, Altman DG, et al. Strengthening the Reporting of Observational Studies in Epidemiology (STROBE): explanation and elaboration. Epidemiology. 2007; 18:805-35.

13. Maas AIR, Hukkelhoven CWPM, Marshall LF, Steyerberg EW. Prediction of outcome in traumatic brain injury with computed tomographic characteristics: a comparison between the computed tomographic classification and combinations of computed tomographic predictors. Neurosurgery. 2005;57:1173-82.

14. Aries MJH, Czosnyka M, Budohoski KP, et al. Continuous determination of optimal cerebral perfusion pressure in traumatic brain injury. Crit Care Med. 2012;40:2456-63.

15. Steiner LA, Czosnyka M, Piechnik SK, et al. Continuous monitoring of cerebrovascular pressure reactivity allows determination of optimal cerebral perfusion pressure in patients with traumatic brain injury. Crit Care Med. 2002;30:733-8.

16. Patel HC, Menon DK, Tebbs S, Hawker R, Hutchinson PJ, Kirkpatrick PJ. Specialist neurocritical care and outcome from head injury. Intensive Care Med. 2002;28:547-53.

17. Smielewski P, Aries M, Lavinio A, et al. Use of ICM+ Software for tracking "Optimal" CPP values in real time. Eur J Anaesthesiol. 2012;29:A34.

18. ARDS Definition Task Force, Ranieri VM, Rubenfeld GD, et al. Acute respiratory distress syndrome: the Berlin definition. JAMA. 2012;307:2526-33.

19. Aisiku IP, Yamal J-M, Doshi P, et al. The incidence of ARDS and associated mortality in severe TBI using the Berlin definition. J Trauma Acute Care Surg. 2016;80:308-12.

20. Contant CF, Valadka AB, Gopinath SP, Hannay HJ, Robertson CS. Adult respiratory distress syndrome: a complication of induced hypertension after severe head injury. J Neurosurg. 2001;95:560-8.

21. Amato MBP, Meade MO, Slutsky AS, et al. Driving pressure and survival in the acute respiratory distress syndrome. N Engl J Med. 2015;372:747-55.
22. Guérin C, Papazian L, Reignier J, et al. Effect of driving pressure on mortality in ARDS patients during lung protective mechanical ventilation in two randomized controlled trials. Crit Care. 2016;20:38

23. Tejerina E, Pelosi P, Muriel A, et al. Association between ventilatory settings and development of acute respiratory distress syndrome in mechanically ventilated patients due to brain injury. J Crit Care. 2017;38:341-5.

24. Oddo M, Nduom E, Frangos S, et al. Acute lung injury is an independent risk factor for brain hypoxia after severe traumatic brain injury. Neurosurgery. 2010;67:338-44.

25. Go SL, Singh JM. Pro/con debate: should $\mathrm{PaCO} 2$ be tightly controlled in all patients with acute brain injuries? Crit Care. 2013; 17:202.

26. Rangel-Castilla L, Lara LR, Gopinath S, Swank PR, Valadka A, Robertson C. Cerebral hemodynamic effects of acute hyperoxia and hyperventilation after severe traumatic brain injury. J Neurotrauma. 2010;27:1853-63.

27. Meng L, Gelb AW. Regulation of cerebral autoregulation by carbon dioxide. Anesthesiology. 2015;122:196-205.

28. Burchiel KJ, Steege TD, Wyler AR. Intracranial pressure changes in brain-injured patients requiring positive end-expiratory pressure ventilation. Neurosurgery. 1981;8:443-9.

29. Shapiro HM, Marshall LF. Intracranial pressure responses to PEEP in head-injured patients. J Trauma. 1978;18:254-6.

30. Videtta W, Villarejo F, Cohen M, et al. Effects of positive endexpiratory pressure on intracranial pressure and cerebral perfusion pressure. Acta Neurochir Suppl. 2002;81:93-7.

31. Caricato A, Conti G, Della Corte F, et al. Effects of PEEP on the intracranial system of patients with head injury and subarachnoid hemorrhage: the role of respiratory system compliance. J Trauma. 2005;58:571-6.

32. Sorrentino E, Diedler J, Kasprowicz M, et al. Critical thresholds for cerebrovascular reactivity after traumatic brain injury. Neurocrit Care. 2012;16:258-66 